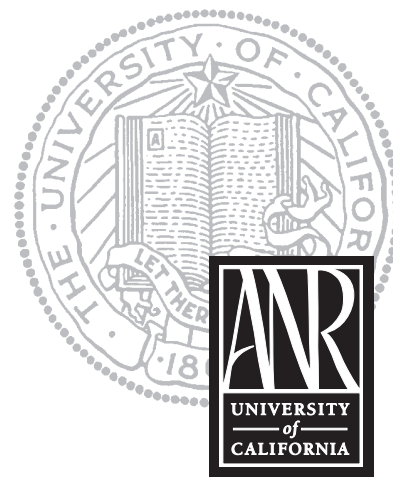

UNIVERSITY OF CALIFORNIA

Division of Agriculture and Natural Resources

http://anrcatalog.ucdavis.edu

\title{
Peppers
}

\section{Safe Methods to Store, Preserve, and Enjoy}

Content reviewed and revised by LINDA J. HARRIS, Food Safety and Applied Microbiology Specialist, Department of Food Science and Technology, University of California, Davis.

Peppers have grown in popularity in recent years, and a wide variety are now available in neighborhood grocery stores. Native to the Americas, most varieties belong to the Capsicum annuum species. Almost all peppers turn from green to yellow, orange, red, or purple when they are fully ripe. Green bell peppers are often harvested before they are ripe and are usually less expensive because they can better withstand transport and tend to last longer.

Peppers range in pungency from the sweet bell to the fiery habanero. The chemical substance that makes some peppers hot is capsaicin (pronounced "kap-'say-isin"). Each type of hot pepper has its own distinctive flavor and level of hotness.

\section{SAFETY TIPS FOR PRESERVING PEPPERS}

CAUTION: The volatile oils in hot peppers can cause burns. When working with hot peppers it is advisable to wear gloves. Do not touch eyes with contaminated hands.

It is a common misconception that the hotter the pepper, the more acidic it is. The hotness of a pepper depends on the amount of capsaicin it contains and not on the level of acidity. All peppers are classified as low-acid foods and have a $\mathrm{pH}$ of 4.8 to 6.0 depending on maturity and variety.

When pickling or canning peppers, it is important to follow recipe directions carefully. Peppers preserved improperly at home have caused botulism. Never taste food that appears to be spoiled. If the contents of the jar appear gassy, mushy, moldy, or have a disagreeable odor, discard the food carefully. Boil the jar, lid, and contents for 30 minutes in water. Thoroughly scrub all counters, containers, equipment (including can openers), clothing, and hands that may have come in contact with the food or containers. Do not reuse sponges or towels that may have been used in the cleanup. Place them in a plastic bag and discard it in the trash. If someone has

In the early 1900 s, Wilbur L. Scoville devised a test to determine the relative hotness of different peppers. Capsaicin from a known weight of pepper was extracted with alcohol and mixed to various concentrations with sweetened water. Human tasters were asked to determine the point at which the water neutralized the hotness. A rating (in Scoville units) was assigned based on the volume of water required to neutralize the hotness. In the early 1980s this technique was replaced by a high-pressure liquid chromatography test that measures the amount of capsaicin more accurately. Because of tradition these measurements are still expressed in Scoville units.

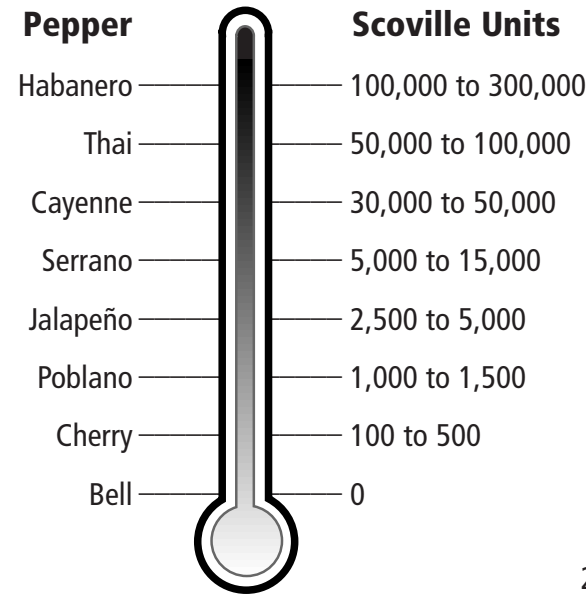


tasted questionable food and becomes ill, contact a doctor and the local health department immediately. If possible, save the jar of questionable food for health officials to examine.

\section{STORING FRESH PEPPERS}

The ideal storage temperature for fresh peppers is $45^{\circ} \mathrm{F}\left(7.3^{\circ} \mathrm{C}\right)$, but they will last about 1 week in a typical home refrigerator (which should be at $40^{\circ} \mathrm{F}$ or $4.5^{\circ} \mathrm{C}$ ). Fresh, whole peppers will last longer if they are kept dry.

Like most fruits and vegetables, peppers should be washed just prior to consuming or preserving. To wash, rinse well under clean, cold water, gently rubbing to remove dirt or soil. Cut or chop on a clean surface using a clean knife. Any cut fruits or vegetables (including prepared salads or produce platters) should be stored in the refrigerator if not used within 2 hours. Once cut, fruits and vegetables are very susceptible to spoilage. Almost all cut produce can support the growth of microorganisms (including some pathogens) when stored at room temperature.

\section{FREEZING PEPPERS}

\section{Plain Peppers}

Peppers lose their crispness when frozen and thawed. Frozen peppers are useful in cooked dishes where texture is not important but the pepper's flavor is desirable. Unlike most vegetables, they do not require blanching before freezing. Peppers can be sliced or diced, quick frozen on a cookie sheet, and packed into moisture- and vapor-proof containers.

\section{Roasted Peppers}

Covering roasted peppers in oil and storing them at room temperature is not a safe practice. It can lead to botulism. Freezing is the preferred method to preserve roasted peppers.

Roasted red bell peppers, popular in many recipes, can be prepared in advance and frozen. Anaheim peppers can also be prepared in advance and frozen for use in chiles rellenos.

1. To peel, first heat in a gas flame, on the barbecue, or under the broiler until the skins separate from the flesh. Then cover peppers in a bowl for 5 to 10 minutes. Skins will slip off easily.

2. Remove stem and seeds.

3. Flatten whole peppers to remove air, or cut peppers into strips or other convenient pieces.

4. Pack prepared peppers into moisture- and vapor-proof packaging, excluding as much air as possible. A sheet of waxed paper or plastic wrap between peppers will make them easier to handle when thawing.

5. Label and freeze at or below $0^{\circ} \mathrm{F}\left(-17.9^{\circ} \mathrm{C}\right)$. Frozen peppers will maintain their quality for 9 months.

Research on food preservation is ongoing - recommendations may change. Make sure your information is always current. Always follow up-to-date, tested guidelines and recipes from reliable sources. 


\section{Sun-Drying}

Day temperatures should be higher than $85^{\circ} \mathrm{F}\left(29.7^{\circ} \mathrm{C}\right)$. If night temperatures drop enough to cause dew to form on the grass (dew point), bring the peppers indoors. Large peppers dry better if they are cut in half. Remove seeds, stems, and membranes. Then slice or cut into cubes. Small peppers can be left whole but should be slit with a knife to speed drying. Peppers are dried completely when brittle.

\section{Air-Drying}

To air-dry peppers, first slit them with a knife. Then use a large needle to run a heavy thread through the stems of the peppers. Hang the strings of peppers in a room where the air circulates freely. High humidity can cause the peppers to spoil before they dry. This method can take as long as 3 to 4 weeks.

\section{Dehydrating}

Dehydrator or oven temperatures should not exceed $140^{\circ} \mathrm{F}\left(60.5^{\circ} \mathrm{C}\right)$. Large peppers dry better if they are first cut in half. Remove seeds, stems, and membranes. Then slice or cut into cubes.

\section{PICKLING PEPPERS}

All types of peppers can be pickled. They are low in acid and must be properly acidified if they are to be safely processed in a water bath canner. The lower temperatures used in pickling help to preserve the crispness of the peppers. Follow recipe directions carefully (see "General Instructions for Processing Pickled Peppers in a Water Bath Canner") to ensure a safe, quality product.

\section{Use the Right Equipment}

- Select canning jars and lids as carefully for pickling as you would for canning. Wash jars in hot, soapy water, and rinse well. Discard jars with chips or cracks. Always use new lids. Ring bands can be reused, but replace those with dents or rust.

- A water bath canner or deep kettle is necessary for processing. The kettle should be deep enough so that the tops of the jars can be covered with water. A rack should be placed on the bottom of the kettle to prevent jars from touching the bottom of the kettle and to allow water to circulate.

\section{Use the Right Ingredients}

Peppers. Choose peppers that are firm, fresh, and free from bruises, blemishes, and insect damage. Preserve as soon as possible after harvesting. An average of 9 pounds ( $4 \mathrm{~kg}$ ) is needed per canner load of nine 1-pint (500-ml) jars. It is possible to adjust the intensity of pickled peppers by using all hot peppers or blending the hot peppers with sweet bell peppers. However, don't change the total amount of peppers required in the recipe.

Salt. Use only plain salt designated as canning or pickling salt. Do not use table salt.

Research on food preservation is ongoing - recommendations may change. Make sure your information is always current. Always follow up-to-date, tested guidelines and recipes from reliable sources.
Table salt contains additives to keep the salt free-flowing in damp weather. These additives can make the pickling liquids cloudy. The iodine in iodized salt tends to darken the peppers. The salt in pickled peppers is used for seasoning and can be safely omitted by those on sodium-restricted diets.

Vinegar. Use a good, clear, standard vinegar, free from sediment, with at least 5 percent acetic acid (50-grain strength). Distilled white vinegar helps to keep the original color of the peppers. Cider, wine, and malt vinegars can darken the peppers 
slightly but may be used if desired. Do not use homemade vinegar unless it has been tested to determine the percentage of acid. To prevent loss of acetic acid, avoid long boiling of the vinegar solution.

\section{General Instructions for Processing Pickled Peppers in a Water Bath Canner}

1. Prepare lids according to the manufacturer's instructions.

2. Fill clean jars with peppers to within $1 / 2$ inch $(1 \mathrm{~cm})$ of the rim of the jar.

3. Cover the peppers with hot liquid or brine. Be sure to leave the $1 / 2$ inch $(1 \mathrm{~cm})$ of headspace. (Headspace is the distance between the contents and the rim of the jar.)

4. Remove air bubbles by running a plastic knife or spatula between the food and the jar.

5. Clean the rim and threads of the jar with a clean, damp cloth.

6. Place a heated lid on the jar and secure it (finger tight) with a ring band. Follow manufacturer's instructions.

7. Place jars in a water bath canner or deep kettle with a rack. The rack can be made of wire or wood. It should prevent the jars from touching the bottom of the kettle and allow the water to circulate. Fill the water bath canner to about half full before loading. Water should be very hot but not boiling. Add enough water to cover the tops of the jars by at least 1 inch $(2.5 \mathrm{~cm})$.

8. Begin to count processing time when the water bath temperature reaches a gentle boil $\left(180^{\circ} \mathrm{F}\right.$ or $\left.83^{\circ} \mathrm{C}\right)$. Process for the time indicated in the recipe. Do NOT substitute larger jars as this can result in under processing and an unsafe product. If you live at an altitude of higher than 1,000 feet $(305 \mathrm{~m})$ above sea level, processing times will be longer. Use the table provided for each recipe to adjust the processing time.

9. As you remove the jars from the water bath, hold them level, but do not disturb the seal. Leave the ring bands on the jars until they have cooled thoroughly.

10. Place the hot jars of peppers, well separated, on a rack or folded towel away from drafts or cool surfaces. Allow the jars to cool undisturbed for 24 hours. Then remove the ring bands before storing.

11. If lids have not sealed, store the jars of peppers in the refrigerator or reprocess them. Reprocessing can lower the quality of the finished product.

12. When jars have cooled completely, check the lids to be sure they have a good seal. If the lids have sealed properly, you should be able to lift the jars by the lids after removing the ring bands. The lid should be concave and should not give when pressed in the center.

\section{CANNING UNPICKLED ROASTED PEPPERS}

Research on food preservation is ongoing - recommendations may change. Make sure your information is always current. Always follow up-to-date, tested guidelines and recipes from reliable sources.
Because they are low-acid vegetables, peppers must always be canned in a pressure canner if they are not pickled. Follow manufacturer's instructions for proper use of a pressure canner.

1. Tough-skinned peppers. Peel peppers by first heating them in a gas flame, on the barbecue, or under the broiler until the skins separate from the flesh. Then place peppers in a bowl and cover for 5 to 10 minutes. Skins will slip off easily. Cut off the stem end of each pepper, and remove the core and seeds. 
Other peppers. Remove stems, cores, and seeds; blanch 3 minutes. Quarter large peppers; leave small peppers whole but flatten them before packing into jars.

2. Pack into half-pint (250-ml) or 1-pint (500-ml) jars. Do not use quart (1-L) jars. Cover peppers with boiling water, leaving a 1 inch of headspace. Then add $1 / 2$ teaspoon $(2 \mathrm{ml})$ of salt to pint jars, if desired.

3. Important: Add 1 tablespoon $(15 \mathrm{ml})$ of bottled lemon juice to each 1-pint (500-ml) jar.

4. Remove air bubbles by running a plastic knife or spatula between the peppers and the jar. Wipe jar rims with a clean, damp cloth and secure lids and ring bands.

5. Process in a properly functioning pressure canner as prescribed in Table 1.

\section{STORING CANNEDAND PICKLED PEPPERS}

1. Store sealed jars of peppers in a cool, dry, dark place. Quality is best maintained when storage temperatures do not exceed $75^{\circ} \mathrm{F}\left(24.1^{\circ} \mathrm{C}\right)$.

2. Store opened jars of peppers in the refrigerator.

Table 1. Recommended Time in a Pressure Canner for Unpickled Peppers

\begin{tabular}{|c|c|c|c|c|c|c|c|}
\hline \multirow[b]{3}{*}{ Jar Size } & \multirow[b]{3}{*}{$\begin{array}{l}\text { Time } \\
\text { (min) }\end{array}$} & \multicolumn{6}{|c|}{ Canner Gauge Pressure at Altitudes of } \\
\hline & & \multicolumn{4}{|c|}{ Dial Gauge Canner } & \multicolumn{2}{|c|}{ Weighted Gauge Canner } \\
\hline & & $\begin{array}{l}0- \\
2,000 \mathrm{ft} \\
\text { (lb) }\end{array}$ & $\begin{array}{l}2,001- \\
4,000 \mathrm{ft} \\
\text { (lb) }\end{array}$ & $\begin{array}{l}4,001- \\
6,000 \mathrm{ft} \\
\text { (lb) }\end{array}$ & $\begin{array}{l}6,001- \\
8,000 \mathrm{ft} \\
\text { (lb) }\end{array}$ & $\begin{array}{l}0- \\
1,000 \mathrm{ft} \\
\text { (lb) }\end{array}$ & $\begin{array}{l}\text { above } \\
1,000 \mathrm{ft} \\
\text { (lb) }\end{array}$ \\
\hline $\begin{array}{l}\text { half-pint } \\
\text { or pint }\end{array}$ & 35 & 11 & 12 & 13 & 14 & 10 & 15 \\
\hline Jar Size & $\begin{array}{l}\text { Time } \\
\text { (min) }\end{array}$ & $\begin{array}{l}0- \\
610 \mathrm{~m} \\
(\mathrm{KPa})\end{array}$ & $\begin{array}{l}611- \\
1,220 \mathrm{~m} \\
(\mathrm{KPa})\end{array}$ & $\begin{array}{l}1,221- \\
1,830 \mathrm{~m} \\
(\mathrm{KPa})\end{array}$ & $\begin{array}{l}1,831- \\
2,440 \mathrm{~m} \\
(\mathrm{KPa})\end{array}$ & $\begin{array}{l}0- \\
305 \mathrm{~m} \\
(\mathrm{KPa})\end{array}$ & $\begin{array}{l}\text { above } \\
\mathbf{3 0 5} \mathrm{m} \\
(\mathrm{KPa})\end{array}$ \\
\hline $\begin{array}{l}250-\mathrm{ml} \text { or } \\
500-\mathrm{ml}\end{array}$ & 35 & 75 & 82 & 89 & 95 & 68 & 102 \\
\hline
\end{tabular}

Adapted from the series, "Let's Preserve Peppers," Pennsylvania State University Cooperative Extension.

Research on food preservation is ongoing - recommendations may change. Make sure your information is always current. Always follow up-to-date, tested guidelines and recipes from reliable sources. 


\section{SWEET PICKLED PEPPERS}

Makes nine 1-pint (500-ml) jars.

$\begin{array}{lll}7 \mathrm{lb} & \text { bell peppers } & 3.2 \mathrm{~kg} \\ 3 \text { cups } & \text { vinegar (5\%) } & 750 \mathrm{ml} \\ 3 \text { cups } & \text { water } & 750 \mathrm{ml} \\ 31 / 2 \text { cups } & \text { sugar } & 875 \mathrm{ml} \\ 9 & \text { garlic cloves } & 9 \\ 41 / 2 \mathrm{tsp} & \text { canning or pickling salt } & 25 \mathrm{ml}\end{array}$

CAUTION: The volatile oils in hot peppers can cause burns. When working with hot peppers it is advisable to wear gloves. Do not touch eyes with contaminated hands.

$\bullet \cdot \cdots \cdots \cdot \cdots \cdot \cdots \cdot \cdots \cdot \bullet$

1. Select and wash your favorite bell peppers. Cut into quarters, remove cores and seeds, and cut away any blemishes. Slice peppers into strips.

2. Boil vinegar, water, and sugar for 1 minute. Add peppers and bring just to a boil.

3. Place 1 garlic clove and $1 / 2 \mathrm{tsp}(2 \mathrm{ml})$ salt into each sterile 1-pint (500-ml) canning jar.

4. Remove peppers and pack them into jars, leaving $1 / 2$ inch $(1 \mathrm{~cm})$ of headspace.

5. Cover the peppers with the hot vinegar mixture, again leaving $1 / 2$ inch $(1 \mathrm{~cm})$ of headspace.

6. Remove air bubbles by running a plastic knife or spatula between the food and the jar. Then wipe jar rims with a clean, damp cloth and secure lids and ring bands.

7. Process pints in a boiling water bath as prescribed in Table 2 .

Table 2. Recommended Processing Time for Sweet Pickled Peppers in a Water Bath Canner

\begin{tabular}{llll}
\hline & \multicolumn{2}{l}{ Processing Time at Altitudes of } \\
\cline { 2 - 4 } Jar Size & $\mathbf{0 - 1 , 0 0 0 ~ f t}$ & $\mathbf{1 , 0 0 1 - 6 , 0 0 0 ~ f t ~}$ & above $\mathbf{6 , 0 0 0} \mathbf{f t}$ \\
\hline half-pint or pint & $5 \mathrm{~min}$ & $10 \mathrm{~min}$ & $15 \mathrm{~min}$ \\
\hline
\end{tabular}

Adapted from the series, "Let's Preserve Peppers," Pennsylvania State University Cooperative Extension.

Research on food preservation is ongoing - recommendations may change. Make sure your information is always current. Always follow up-to-date, tested guidelines and recipes from reliable sources. 


\section{HOT PICKLED PEPPERS}

Makes nine 1-pint (500-ml) jars.

$\begin{array}{lll}4 \mathrm{lb} & \text { hot red, green, or yellow peppers } & 1.8 \mathrm{~kg} \\ 1 \frac{1 / 2 \mathrm{lb}}{1 / 2 \mathrm{lb}} & \text { green bell peppers } & 0.7 \mathrm{~kg} \\ 5 \mathrm{cups} & \text { red bell peppers } & 0.7 \mathrm{~kg} \\ 1 \mathrm{cup} & \text { vinegar }(5 \%) & 1.25 \mathrm{~L} \\ 2 \mathrm{tsp} & \text { water } & 250 \mathrm{ml} \\ 4 \mathrm{tsp} & \text { canar } & 10 \mathrm{ml} \\ 2 & \text { cloves garlic } & 20 \mathrm{ml}\end{array}$

1. Select and wash your favorite peppers. Cut bell peppers into quarters, remove cores and seeds, and slice.

CAUTION: The volatile oils in hot peppers can cause burns. When working with hot peppers it is advisable to wear gloves. Do not touch eyes with contaminated hands.

2. Peel tough-skinned peppers (if desired): slash 2 to 4 slits in each pepper and heat in a gas flame, on the barbecue, or under the broiler until the skins separate from the flesh. Then place peppers in a bowl and cover for 5 to 10 minutes. Skins will slip off easily.

3. Small peppers can be kept whole but should be flattened. Cut larger peppers into quarters.

4. Pack peppers into canning jars, leaving $1 / 2$ inch $(1 \mathrm{~cm})$ of headspace.

5. Combine and heat vinegar, water, sugar, salt, and garlic. Simmer 10 minutes. Remove garlic.

6. Pour pickling solution over peppers, again leaving $1 / 2$ inch $(1 \mathrm{~cm})$ of headspace.

7. Remove air bubbles by running a plastic knife or spatula between the food and the jar. Then wipe jar rims with a clean, damp cloth, and secure lids and ring bands.

8. Process pints in a boiling water bath as prescribed in Table 3.

Table 3. Recommended Processing Time for Hot Pickled Peppers in a Water Bath Canner

\begin{tabular}{llll}
\hline & \multicolumn{2}{l}{ Processing Time at Altitudes of } \\
\cline { 2 - 4 } Jar Size & $\mathbf{0 - 1 , 0 0 0 ~ f t ~}$ & $\mathbf{1 , 0 0 1 - 6 , 0 0 0 ~ f t ~}$ & above $\mathbf{6 , 0 0 0} \mathbf{f t}$ \\
\hline half-pint or pint & $10 \mathrm{~min}$ & $15 \mathrm{~min}$ & $20 \mathrm{~min}$ \\
\hline Adapted from the series, "Let's Preserve Peppers," Pennsylvania State University Cooperative Extension &
\end{tabular}

Research on food preservaAdapted from the series, "Let's Preserve Peppers," Pennsylvania State University Cooperative Extension.

tion is ongoing - recommendations may change. Make sure your information is always current. Always follow up-to-date, tested guidelines and recipes from reliable sources. 


\section{HOT CHILI SALSA}

Makes six to eight 1-pint (500-ml) jars.

$\begin{array}{lll}1 \mathrm{lb} & \text { onions } & 450 \mathrm{~g} \\ 2 \mathrm{lb} & \text { hot peppers } & 900 \mathrm{~g} \\ 5 \mathrm{lb} & \text { tomatoes (fresh or canned) } & 2.3 \mathrm{~kg} \\ 3 \mathrm{tsp} & \text { canning or pickling salt } & 15 \mathrm{ml} \\ 1 / 2 \mathrm{tsp} & \text { ground black pepper } & 2 \mathrm{ml} \\ 1 \mathrm{cup} & \text { vinegar (5\%) } & 250 \mathrm{ml}\end{array}$

The hotness of the salsa depends on the kind and amount of peppers used. For a very mild salsa, substitute bell peppers for hot peppers. The mix of peppers can be varied as long as the total amount is not changed.

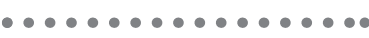

CAUTION: The volatile oils in hot peppers can cause burns. When working with hot peppers it is advisable to wear gloves. Do not touch eyes with contaminated hands.
Research on food preservation is ongoing - recommendations may change. Make sure your information is always current. Always follow up-to-date, tested guidelines and recipes from reliable sources.

\begin{tabular}{|c|c|c|c|}
\hline \multirow[b]{2}{*}{ Jar Size } & \multicolumn{3}{|c|}{ Processing Time at Altitudes of } \\
\hline & $0-1,000 \mathrm{ft}$ & $1,001-6,000 \mathrm{ft}$ & above $6,000 \mathrm{ft}$ \\
\hline half-pint or pint & $15 \min$ & $20 \mathrm{~min}$ & $25 \mathrm{~min}$ \\
\hline
\end{tabular}

1. Finely chop or coarsely grind onions and peppers. Peel tomatoes, if desired, and chop them into small pieces.

2. Add onions, peppers, and other ingredients to chopped tomatoes. Heat to simmering; simmer 10 minutes.

3. Pack into clean, 1-pint $(500-\mathrm{ml})$ jars, leaving $1 / 2$ inch $(1 \mathrm{~cm})$ of headspace. Wipe jar rims with a clean, damp cloth, and secure lids and ring bands.

4. Process pints in a boiling water bath as prescribed in Table 4.

\section{Table 4. Recommended Processing Time for Hot Chili Salsa in a Water Bath Canner}




\section{MARINATED PEPPERS}

Makes 9 half-pint (250-ml) jars.

$\begin{array}{lll}4 \mathrm{lb} & \text { firm peppers } & 1.8 \mathrm{~kg} \\ 1 / 2 \mathrm{cup} & \text { chopped onions } & 125 \mathrm{ml} \\ 1 \mathrm{tbsp} & \text { dried oregano leaves } & 15 \mathrm{ml} \\ 1 \mathrm{cup} & \text { bottled lemon juice } & 250 \mathrm{ml} \\ 2 \mathrm{cups} & \text { vinegar (5\%) } & 500 \mathrm{ml} \\ 2 \mathrm{tbsp} & \text { prepared horseradish (optional) } & 30 \mathrm{ml} \\ 2-3 & \text { cloves garlic, quartered (optional) } & 2-3 \\ 1 \text { cup } & \text { olive or salad oil } & 250 \mathrm{ml}\end{array}$

CAUTION: The volatile oils in hot peppers can cause burns. When working with hot peppers it is advisable to wear gloves. Do not touch eyes with contaminated hands.
1. Select and wash your favorite sweet bell or hot peppers.

2. Small peppers can be left whole but should be flattened. Large peppers should be quartered. Slash 2 to 4 slits in each pepper. Peel tough-skinned peppers by first heating in a gas flame, on the barbecue, or under the broiler until the skins separate from the flesh. Then place peppers in a bowl and cover for 5 to $10 \mathrm{~min}$ utes. Skins will slip off easily. Blanch other peppers for 3 minutes in boiling water.

3. Mix onions, oregano, lemon juice, vinegar, and horseradish in a saucepan and heat to boiling.

4. Place $1 / 4$ garlic clove in each half-pint $(250-\mathrm{ml})$ jar or $1 / 2$ clove in each 1-pint (500-ml) jar.

5. If desired, add $1 / 4$ teaspoon $(1 \mathrm{ml})$ salt to each half-pint (250-ml) jar; $1 \frac{1}{2}$ teaspoon $(2 \mathrm{ml})$ to each 1-pint (500-ml) jar.

6. Fill jars with peppers to $1 / 2$ inch $(1 \mathrm{~cm})$ from the top.

7. Place 2 tablespoons $(30 \mathrm{ml}$ ) of oil in each jar.

8. Pour hot, well-mixed, vinegar solution over peppers, leaving $1 / 2$ inch $(1 \mathrm{~cm})$ of headspace.

9. Remove air bubbles by running a plastic knife or spatula between the food and the jar. Then wipe jar rims with a clean, damp cloth and secure lids and ring bands.

10. Process in a boiling water bath as prescribed in Table 5 .

\section{Table 5. Recommended Processing Time for Marinated Peppers in a Water Bath Canner}

Research on food preservation is ongoing - recommendations may change. Make sure your information is always current. Always follow up-to-date, tested guidelines and recipes from reliable sources.

\begin{tabular}{llll}
\hline & \multicolumn{2}{l}{ Processing Time at Altitudes of } \\
\cline { 2 - 4 } Jar Size & $\mathbf{0 - 1 , 0 0 0 ~ f t ~}$ & $\mathbf{1 , 0 0 1 - 6 , 0 0 0 ~ f t ~}$ & above 6,000 ft \\
\hline half-pint or pint & $15 \mathrm{~min}$ & $20 \mathrm{~min}$ & $25 \mathrm{~min}$ \\
\hline
\end{tabular}

Adapted from "So Easy to Preserve," 2nd Edition, Cooperative Extension Service, University of Georgia, and "Let's Preserve Peppers," Pennsylvania State University Cooperative Extension. 


\section{PEPPER RELISH}

Makes four to five 1-pint (500-ml) jars.

$\begin{array}{lll}16 \text { cups } & \begin{array}{l}\text { ground red and green bell peppers } \\ \text { (including juice) }\end{array} & 4 \mathrm{~L} \\ 4 \frac{1}{2} \text { cups } & \text { ground onions } & 1.125 \mathrm{~L} \\ 3 \text { cups } & \text { sugar } & 750 \mathrm{ml} \\ 3 \text { cups } & \text { white vinegar (5\%) } & 750 \mathrm{ml} \\ 2 \text { tbsp } & \text { mustard seeds } & 30 \mathrm{ml} \\ 2 \text { tbsp } & \text { salt } & 30 \mathrm{ml}\end{array}$

1. Combine all ingredients. Boil 30 minutes, uncovered.

CAUTION: The volatile oils in hot peppers can cause burns. When working with hot peppers it is advisable to wear gloves. Do not touch eyes with contaminated hands.

2. Pack into jars, to $1 / 2$ inch $(1 \mathrm{~cm})$ from top.

3. Remove air bubbles by running a plastic knife or spatula between the food and the jar. Then wipe jar rims with a clean, damp cloth and secure lids and ring bands.

4. Process pints in a boiling water bath as prescribed in Table 6 .

Table 6. Recommended Processing Time for Pepper Relish in a Water Bath Canner

\begin{tabular}{llll}
\hline & \multicolumn{3}{l}{ Processing Time at Altitudes of } \\
\cline { 2 - 4 } Jar Size & $\mathbf{0 - 1 , 0 0 0 ~ f t ~}$ & $\mathbf{1 , 0 0 1 - 6 , 0 0 0 ~ f t ~}$ & above $\mathbf{6 , 0 0 0} \mathbf{f t}$ \\
\hline half-pint or pint & $10 \mathrm{~min}$ & $15 \mathrm{~min}$ & $20 \mathrm{~min}$ \\
\hline
\end{tabular}

Adapted from "So Easy to Preserve," 2nd Edition, Cooperative Extension Service, University of Georgia.

Research on food preservation is ongoing - recommendations may change. Make sure your information is always current. Always follow up-to-date, tested guidelines and recipes from reliable sources. 


\section{PEPPER JELLY}

Makes 5 half-pint (250-ml) jars.

$\begin{array}{lll}4 \text { or } 5 & \begin{array}{l}\text { jalapeño or other hot peppers, } \\ \text { cored and chopped }\end{array} & 4 \text { or } 5 \\ 4 & \begin{array}{l}\text { medium green or red bell peppers, } \\ \text { cored and chopped }\end{array} & 4 \\ 1 \text { cup } & \text { white vinegar (5\%) } & 250 \mathrm{ml} \\ 5 \text { cups } & \text { sugar } & 1.25 \mathrm{~L} \\ 1 \text { pouch } & \text { liquid pectin } & 1 \text { pouch } \\ 1-2 \text { drops } & \text { green food coloring } & 1-2 \text { drops }\end{array}$

CAUTION: The volatile oils in hot peppers can cause burns. When working with hot peppers it is advisable to wear gloves. Do not touch eyes with contaminated hands.
1. Put half the peppers and half the vinegar into a blender; cover and process until peppers are liquefied. Repeat with remaining peppers and vinegar.

2. Combine the pepper and vinegar mixture with the sugar in a large saucepan and boil slowly for 10 minutes. Remove from heat.

3. Add liquid pectin and boil hard for 1 minute.

4. Skim foam off the top of the jelly and add a few drops of green food coloring. Pour jelly immediately into canning jars, leaving $1 / 4$ inch $(0.5 \mathrm{~cm})$ of headspace.

5. Wipe jar rims with a clean, damp cloth and secure lids and ring bands.

6. Process the jars of jelly in a boiling water bath as prescribed in Table 7 .

Table 7. Recommended Processing Time for Pepper Jelly in a Water Bath Canner

\begin{tabular}{llll}
\hline & \multicolumn{3}{l}{ Processing Time at Altitudes of } \\
\cline { 2 - 4 } Jar Size & $\mathbf{0 - 1 , 0 0 0 ~ f t ~}$ & $\mathbf{1 , 0 0 1 - 6 , 0 0 0 ~ f t ~}$ & above $\mathbf{6 , 0 0 0} \mathbf{f t}$ \\
\hline half-pint or pint & $5 \mathrm{~min}$ & $10 \mathrm{~min}$ & $15 \mathrm{~min}$ \\
\hline
\end{tabular}

Adapted from "So Easy to Preserve," 2nd Edition, Cooperative Extension Service, University of Georgia.

Research on food preservation is ongoing - recommendations may change. Make sure your information is always current. Always follow up-to-date, tested guidelines and recipes from reliable sources. 


\section{APRICOT PEPPER JELLY}

Makes 6 half-pint (250-ml) jars.

\begin{tabular}{|c|c|c|}
\hline $11 / 4$ cups & dried apricot halves, finely slivered & $300 \mathrm{ml}$ \\
\hline 1 cup & $\begin{array}{l}\text { red or green bell pepper strips } \\
\text { (about } 1 \text { medium-size pepper) }\end{array}$ & $250 \mathrm{ml}$ \\
\hline $1 / 3$ cup & $\begin{array}{l}\text { chopped jalapeño or other hot } \\
\text { pepper, stems and seeds removed }\end{array}$ & $75 \mathrm{ml}$ \\
\hline 2 cups & cider vinegar $(5 \%)$ & $500 \mathrm{ml}$ \\
\hline 4 cups & sugar & $1 \mathrm{~L}$ \\
\hline 1 package & powdered fruit pectin & 1 package \\
\hline $1 / 2 \mathrm{tsp}$ & butter or margarine & $2 \mathrm{ml}$ \\
\hline 5 drops & red or green food coloring & 5 drops \\
\hline
\end{tabular}

(depending on the type of pepper used)

1. Cover dried apricots with boiling water. Leave for approximately 10 minutes. Drain.

2. Combine bell pepper strips, chopped hot peppers, drained apricots, and 2 cups $(500 \mathrm{ml})$ vinegar in a food processor or blender. Process until partially ground with small chunks remaining. Pour into a saucepan.

3. Mix $1 / 4$ cup ( $63 \mathrm{ml}$ ) sugar with pectin. Stir into fruit mixture. Add butter and food coloring.

4. Bring to a boil quickly, stirring constantly. Immediately stir in remaining sugar.

5. Bring to a full boil, stirring, and boil hard for 1 minute. Remove from heat.

6. Skim foam off the top. Then ladle jelly into hot half-pint jars, leaving $1 / 4$ inch $(0.5 \mathrm{~cm})$ of headspace.

7. Wipe jar rims with a clean, damp cloth. Secure lids and ring bands, and process in a boiling water bath as prescribed in Table 8 .

Table 8. Recommended Processing Time for Apricot Pepper Jelly in a Water Bath Canner

Research on food preserva-

\begin{tabular}{llll}
\hline & \multicolumn{3}{l}{ Processing Time at Altitudes of } \\
\cline { 2 - 4 } Jar Size & $\mathbf{0 - 1 , 0 0 0 ~ f t}$ & $\mathbf{1 , 0 0 1 - 6 , 0 0 0 ~ f t ~}$ & above $\mathbf{6 , 0 0 0} \mathbf{f t}$ \\
\hline half-pint or pint & $15 \mathrm{~min}$ & $20 \mathrm{~min}$ & $25 \mathrm{~min}$ \\
\hline Contributed by Solano County Master Food Preservers.
\end{tabular}

Contributed by Solano County Master Food Preservers.

tion is ongoing - recommendations may change. Make sure your information is always current. Always follow up-to-date, tested guidelines and recipes from reliable sources. 


\section{ACKN O WLEDGMENTS}

Jeanette Sutherlin, Nutrition Family and Consumer Sciences Advisor, University of California Cooperative Extension; the Fresno County Master Food Preservers; and Wanda Lau are gratefully acknowledged for their assistance in revising this publication.

An electronic version of this publication is available on the DANR Communication Services Web Site at http://anrcatalog.ucdavis.edu.

Publication 8004.

(C) 1998 by the Regents of the University of California, Division of Agriculture and Natural Resources. All rights reserved.

The University of California, in accordance with applicable Federal and State law and University policy, does not discriminate on the basis of race, color, national origin, religion, sex, disability, age, medical condition (cancer-related), ancestry, marital status, citizenship, sexual orientation, or status as a Vietnam-era veteran or special disabled veteran. The University also prohibits sexual harassment. Inquiries regarding the University's nondiscrimination policies may be directed to the Affirmative Action Director, University of California, Agriculture and Natural Resources, 1111 Franklin Street, Oakland, CA 94607-5200; (510) 987-0096.

76-pr-6/98-GM/WS

ISBN 978-1-60107-184-2 